The Free Internet Journal

for Organic Chemistry
Review

Arkivoc 2019, part iii, 79-92

\title{
Recent developments in $\mathrm{C}-\mathrm{H}$ functionalization via $\mathrm{C}-\mathrm{H}$ bond activation using ball milling and transition-metal catalysts
}

\author{
Brindaban C. Ranu,* Tubai Ghosh, and Swapnadeep Jalal \\ School of Chemical Sciences, Indian Association for the Cultivation of Science, Jadavpur, \\ Kolkata - 700 032, India \\ E-mail: ocbcr@iacs.res.in
}

This paper is respectfully dedicated to Professor George A. Kraus

Received 12-25-2018

Accepted 02-17-2019

Published on line $02-28-2019$

\section{Abstract}

The inert $\mathrm{C}-\mathrm{H}$ bond functionalization via bond activation in the presence of transition metals using ball milling is reviewed. The use of several transition metals, such as Pd, Rh, Ru, Co, and Ir are covered in this review for a variety of important functionalizations, including halogenation, amidation, alkynylation, and dehydrogenative coupling, among others. These reactions are performed under mild conditions, usually without any solvent, and in relatively short reaction times.

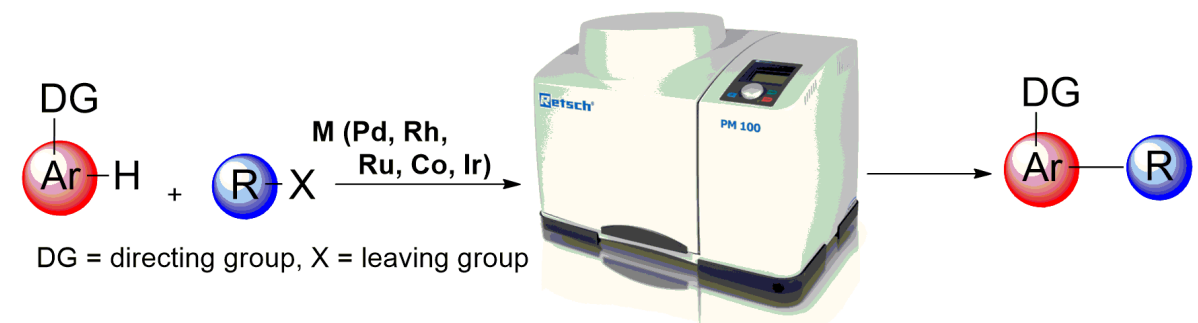

Keywords: $\mathrm{C}-\mathrm{H}$ functionalization, $\mathrm{C}-\mathrm{H}$ bond activation, ball milling, green chemistry, mechanochemistry 


\section{Table of Contents}

1. Introduction

2. Pd-Catalyzed C-H Functionalization

3 Rh-Catalyzed C-H Functionalization

4 Ru-Catalyzed C-H Functionalization

5 Co-Catalyzed C-H Functionalization

6 Ir-Catalyzed C-H Functionalization

7. Conclusions

Acknowledgements

References

Authors' Biographies

\section{Introduction}

The sustainable and environmentally-benign synthesis of organic molecules is of considerable interest. ${ }^{1-3}$ In recent years, significant efforts have been made towards the development of more environmentally-friendly procedures which have more efficiency, cost effectiveness, and minimal chemical waste. The application of mechanical energy to induce organic reactions via grinding, ball milling, shearing and kneading, collectively referred to as mechanochemistry, ${ }^{4-6}$ has emerged as a powerful tool in organic synthesis. Ball-milling reactions are typically operated in a stainless-steel jar with a number of balls (as required for a particular reaction) rotating at high speed $(60-800 \mathrm{rpm})$, using none or a minimum amount of organic solvent, at close to ambient temperature. ${ }^{7}$ Therefore, ball-milling-induced reactions are, in general, cost effective, efficient and 'greener'. Several methods have been reported so far for the synthesis of carbon-carbon and carbonheteroatom bond formation under ball milling via cross-coupling reactions such as Suzuki, Sonogashira, Glaser and others. ${ }^{8,9}$

The transition-metal-catalyzed $\mathrm{C}-\mathrm{H}$ functionalization via $\mathrm{C}-\mathrm{H}$ bond activation has been successfully used for the synthesis of organic molecules, including complex natural products and drugs, as the process eliminates the pre-functionalization step, and, therefore, contributes to step and atom economy. ${ }^{10-17}$ The use of an inert $\mathrm{C}-\mathrm{H}$ bond towards the generation of a functional group is advantageous, as these bonds are the most abundant chemical moieties in organic molecules. Thus, a one-step conversion of a $\mathrm{C}-\mathrm{H}$ bond to the desired functionality reduces the number of synthetic steps, thereby saving reagents, and minimizing the use of solvents and time.$^{18}$ Selective activation of a particular $\mathrm{C}-\mathrm{H}$ bond in an organic molecule out of several similar ones, however, is a challenging task. Therefore, directed $\mathrm{C}-\mathrm{H}$ bond functionalization using an activating group and a suitable transition metal is of current interest. ${ }^{19-22}$ The reaction usually occurs through the formation of an organometallic-metallacycle intermediate that drives the reaction forward. As the ball-milling-induced reactions are operated under relatively mild conditions, the $\mathrm{C}-\mathrm{H}$ functionalization via metallacycle intermediate is expected to proceed smoothly by this technique. We provide here a short review on $\mathrm{C}-\mathrm{H}$ bond functionalization via inert $\mathrm{C}-\mathrm{H}$ bond activation under ball milling addressing only the recent developments beyond a related review on this topic in $2017 .{ }^{23}$ 


\section{Pd-Catalyzed C-H Functionalization}

In 2014, Ćurić and co-workers first reported the $\mathrm{C}-\mathrm{H}$ bond activation of an azobenzene molecule through mechanochemical cyclometallation. Liquid-assisted grinding (LAG) ${ }^{24}$ of a mixture of 4 '-( $N, N$-dimethylamino)-4nitroazobenzene (1) and $\mathrm{Pd}(\mathrm{OAc})_{2}$, with glacial acetic acid as an additive, led to the formation of a dimeric monopalladacycle complex (2) which, on continued grinding with LAG in the presence of an excess of palladium acetate, provided the dicyclopalladated complex (3) (Scheme 1). When the molar ratio of azobenzene to palladium acetate was 1:1, the reaction produced the mono-palladated complex (2); however, the dicyclopalladated complex (3) was formed when two equivalents of $\operatorname{Pd}(\mathrm{OAc})_{2}$ were added to 2 . This method of $\mathrm{C}-\mathrm{H}$ bond activation using $\mathrm{Pd}(\mathrm{II})$ under ball milling demonstrates the feasibility of the mechanochemical process.

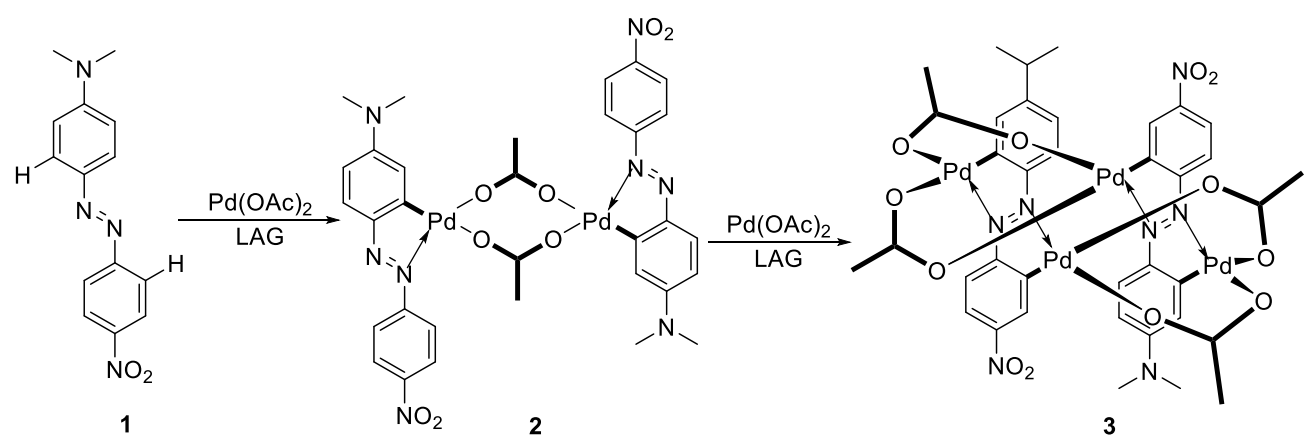

Scheme 1. Palladium-metal-mediated $\mathrm{C}-\mathrm{H}$ bond activation of azobenzene under mechanochemical conditions.

Very recently, Wang's group reported the mechanochemical $\mathrm{C}-\mathrm{H}$ bond halogenation of acetanilides (4) with $N$-halosuccinimides (NXS) under ball milling (Scheme 2) ${ }^{25}$

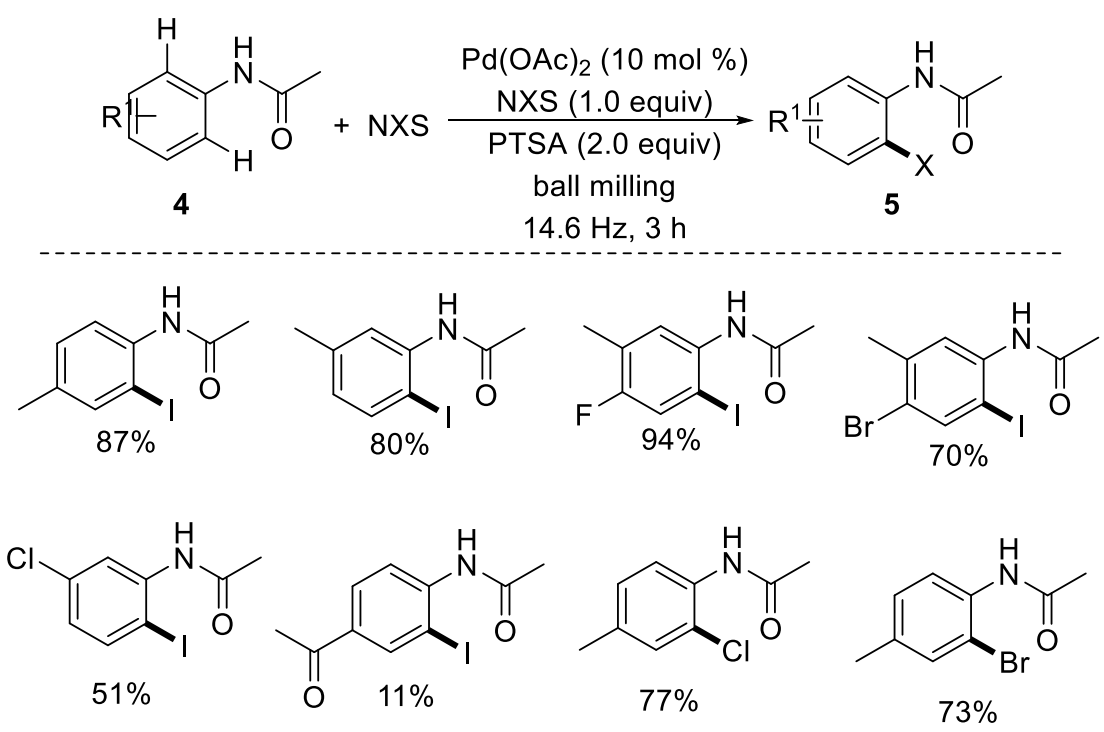

Scheme 2. Mechanochemical Pd-catalyzed ortho-halogenation of acetanilides. 
The combination of palladium acetate along with $p$-toluenesulfonic acid (PTSA) as an additive was found to be essential for the halogenation under solvent-free conditions. The reaction requires the use of an amide as a weakly coordinating directing group. In the case of meta-substituted anilides, the reaction shows high regioselectivity as the reaction occurs selectively at the less-hindered ortho-position. Interestingly, the ortho $\mathrm{C}-\mathrm{H}$ iodinated product was obtained in $90 \%$ yield after milling for $2 \mathrm{~h}$ by using a Retsch MM 200 mixer mill (30 $\mathrm{Hz}$ ). Operation at a milling frequency of $50 \mathrm{~Hz}$ in a Spex Sample Prep 5100 mixer mill afforded the corresponding product in $92 \%$ yield within $1.5 \mathrm{~h}$, which clearly suggests that the use of ball milling at a higher frequency had an effect on the reaction efficiency in terms of reaction time and product yield. The reaction was further applied for the ortho $\mathrm{C}$-H chlorination and bromination of acetanilides using $\mathrm{N}$-chlorosuccinimide (NCS) and $\mathrm{N}$-bromosuccinimide (NBS), under the optimized conditions, to produce the corresponding products in good yield. The use of PTSA was essential for the above transformation, and it was believed that the reaction initially produced the more reactive $\mathrm{Pd}(\mathrm{OTs})_{2}$ from $\mathrm{Pd}(\mathrm{OAc})_{2}$ and $\mathrm{TsOH}$. The active catalyst then interacts with acetanilides to form the six-membered palladacycle, followed by oxidative addition of NXS to form a $\mathrm{Pd}(\mathrm{IV})$ intermediate, which subsequently undergoes reductive elimination to form the product $\mathbf{5}$ with regeneration of the active catalyst.

Xie and co-workers reported the homocoupling of $N$-arylcarbamates (6) under high-speed ball milling through $\mathrm{C}\left(s p^{2}\right)-\mathrm{H}$ bond activation, using weakly coordinating groups in the presence of a palladium catalyst and $\mathrm{Cu}(\mathrm{II})$ as the oxidant (Scheme 3$).^{26}$
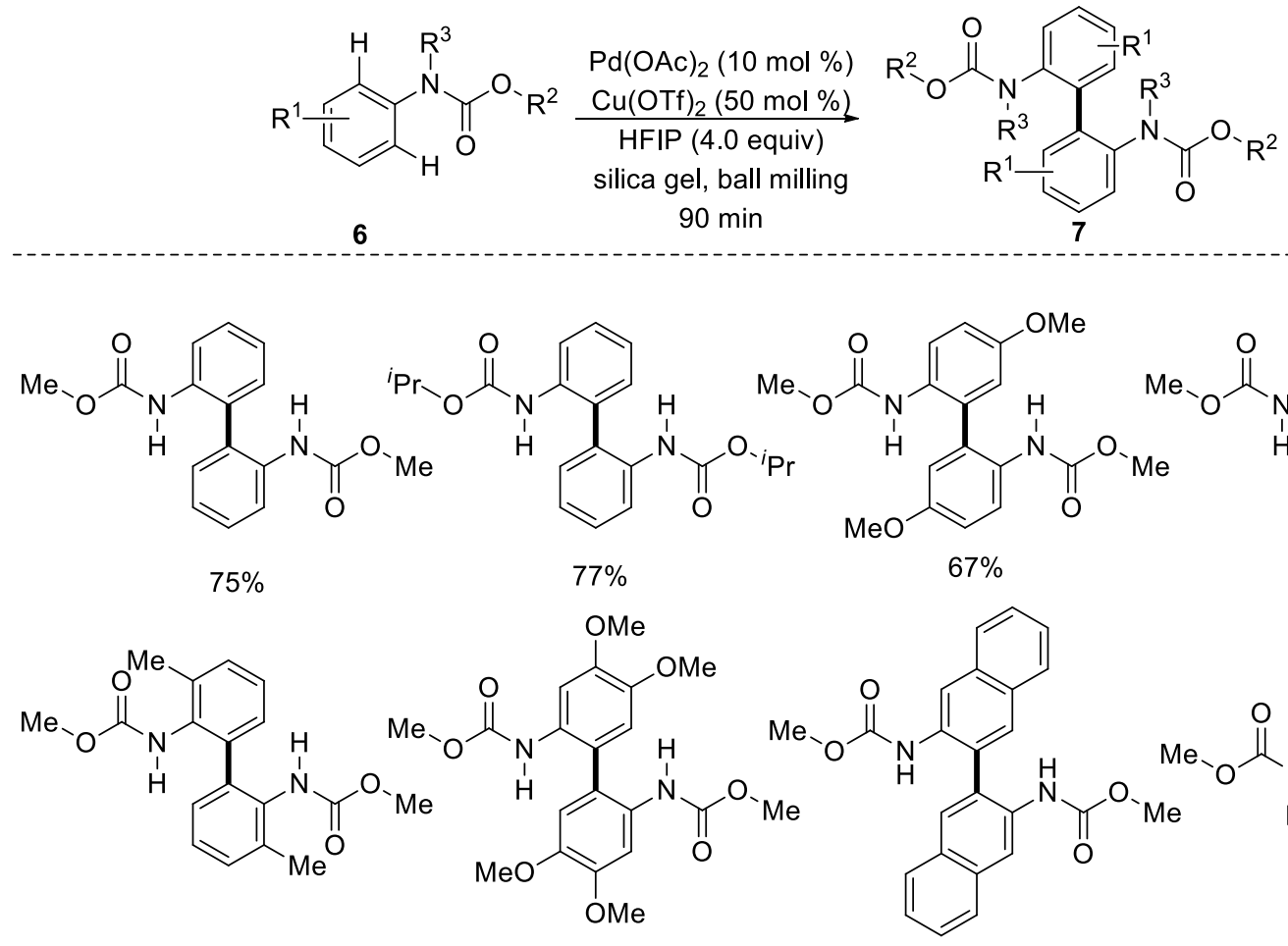

$70 \%$

$67 \%$

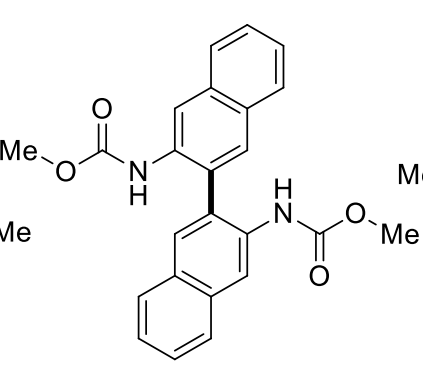

$67 \%$

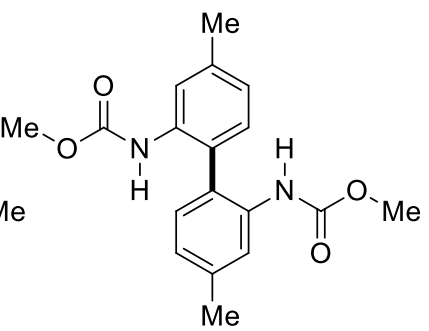

$87 \%$

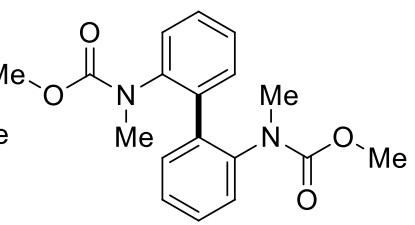

$84 \%$

Scheme 3. Mechanochemical Pd-catalyzed dehydrogenative coupling of $N$-arylcarbamates.

Compared to the reaction carried out in hexafluoroisopropanol (HFIP) as the solvent, the reaction under ball milling proved to be more advantageous. After several optimizations, the best conditions for the dimerization were obtained using 10 mol\% of $\mathrm{Pd}(\mathrm{OAc})_{2}$ as the catalyst and $\mathrm{Cu}(\mathrm{OTf})_{2}$ as the oxidant in the presence of HFIP 
as the additive. The reaction in a stainless-steel vessel with two stainless-steel balls $(d=1.2 \mathrm{~cm})$ for $90 \mathrm{~min}$ at $30 \mathrm{~Hz}$, provided the dimethyl 2,2'-biphenyldicarbamate product in good yield. Dimerized $N$-arylcarbamates (7) were obtained under the optimized conditions. In general, the $N$-phenyl-ring moiety bearing an electrondonating substituent (e.g., $-\mathrm{Me},-\mathrm{OMe},-\mathrm{Et}$, and -OEt), produced higher yields of the products than those bearing electron-withdrawing substituents (e.g., $-\mathrm{Br}$ ). The reaction did not proceed, however, with substrates bearing the relatively strongly electron-withdrawing trifluoromethyl group. Interestingly, when the reaction was performed using two different $\mathrm{N}$-arylcarbamates [e.g., methyl (4-methoxyphenyl)carbamate and methyl p-tolylcarbamate)] under high-speed ball milling in the presence of $\mathrm{Pd}(\mathrm{II})$ salt, the unsymmetrical 2,2'biaryldicarbamate was obtained in $73 \%$ yield. The coupling products, 2,2'-biaryldicarbamates, were easily converted into their corresponding 2,2'-biaryldiamines on base hydrolysis. This $\mathrm{C}-\mathrm{H}$ bond activation under ball milling represents a fast and environmentally-friendly method for the synthesis of 2,2'-biaryldicarbamates and 2,2'-biaryldiamines.

\section{Rh-Catalyzed C-H Functionalization}

In 2015, Bolm and co-workers developed a unique protocol for the mechanochemical synthesis of pentamethylcyclopentadienyl rhodium dichloride $\left[\mathrm{Cp}^{*} \mathrm{RhCl}_{2}\right]_{2}$ under ball milling (Scheme 4). ${ }^{27}$ When a mixture of $\mathrm{RhCl}_{3}$ hydrate (8) and pentamethylcyclopentadiene $(\mathrm{Cp} * \mathrm{H})(9)$ was allowed to stir under liquid-assisted grinding (LAG), the corresponding Rh(III) dimer (10) was obtained in good yield, and within a shorter reaction time compared to the standard solution-based protocol (Scheme 4a).

(a)

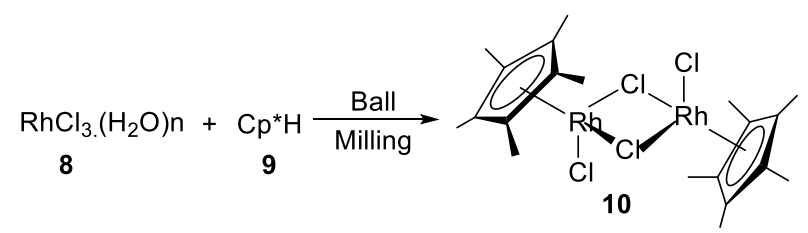

(b)

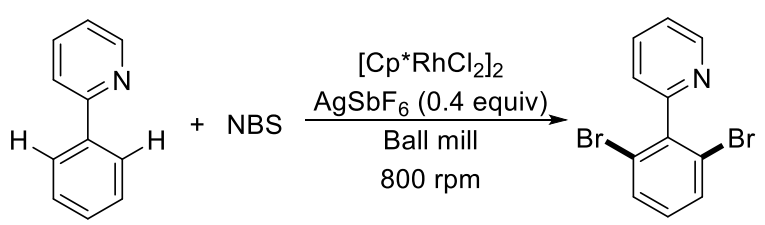

11

$12,74 \%$<smiles>c1ccc(-c2cccc[nH+]2)nc1</smiles>
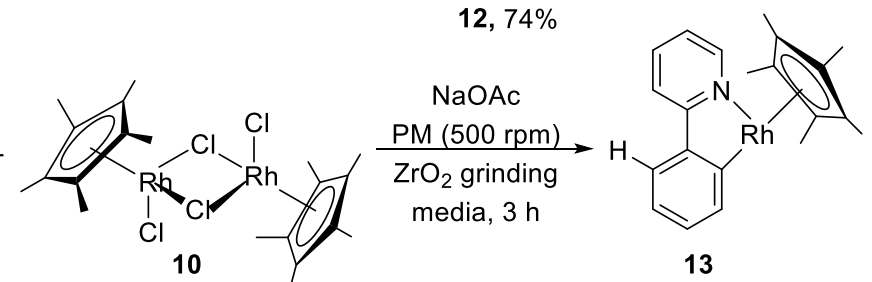

(c)

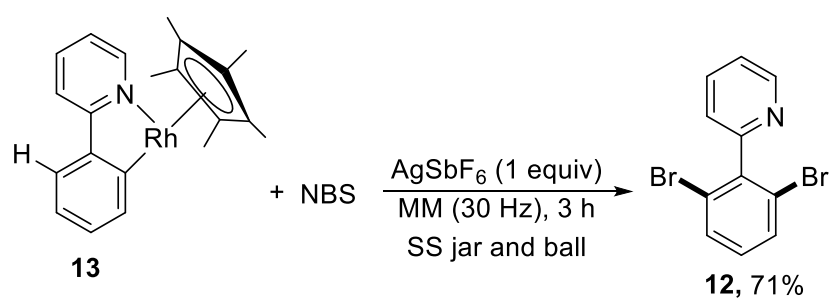

Scheme 4. Mechano-synthesis and application of $\left[\mathrm{Cp}^{*} \mathrm{RhCl}_{2}\right]_{2}$ for $\mathrm{C}-\mathrm{H}$ bond functionalization. 
The newly formed rhodium complex $\left[\mathrm{Cp}^{*} \mathrm{RhCl}_{2}\right]_{2}(10)$ was further applied as a catalyst for the ortho $\mathrm{C}-\mathrm{H}$ bond halogenation of 2-phenylpyridine (11) in the presence of $N$-bromosuccinimide (NBS). The corresponding dibrominated 2-phenylpyridine (12) was formed as the major product in $74 \%$ yield (Scheme $4 \mathrm{~b}$ ). However, a higher reactivity was observed for iodination of 2-phenylpyridine using $N$-iodosuccinimide (NIS). A rhodacycle (13) was formed when 2-phenylpyridine (11) and $\left[\mathrm{Cp}^{*} \mathrm{RhCl}_{2}\right]_{2}(\mathbf{1 0})$ were stirred together in the presence of sodium acetate in a planetary ball mill which, on treatment with NBS and AgSbF6, led to the formation of the dibrominated 2-phenylpyridine (12) as the major product in $71 \%$ yield (Scheme $4 \mathrm{c}$ ). This indicated that the $\mathrm{C}-\mathrm{H}$ bond halogenation may occur via the formation of the intermediate in the original catalytic reaction under ball milling.

Recently, Bolm and co-workers have reported the mechanochemical $\mathrm{C}-\mathrm{H}$ bond amidation of the $\mathrm{C}\left(s p^{2}\right)-\mathrm{H}$ bond using a 1,4,2-dioxazol-5-one as the amidating agent under ball milling (Scheme 5). ${ }^{28}$ The reaction occurs in the presence of $\left[\mathrm{Cp}^{*} \mathrm{RhCl}_{2}\right]_{2}, \mathrm{AgSbF}_{6}$, and $\mathrm{AgOAc}$ under solvent-free conditions using ball milling in a $25 \mathrm{~mL}$ $\mathrm{ZrO}_{2}$ milling jar with one $\mathrm{ZrO}_{2}$ ball of $15 \mathrm{~mm}$ diameter at $30 \mathrm{~Hz}$. It has been found that $\mathrm{Rh}$ is superior to other transition-metal (Ru and $\mathrm{Ir}$ ) catalysts. Under optimized conditions, a library of amide compounds was synthesized starting from diverse, substituted-benzamide substrates as starting materials. In the case of metasubstituted benzamides, the reaction provides a 1.1:1 mixture of the corresponding regioisomers. In general, the reactions resulted in high yields. In the absence of any solvent, the products were obtained in shorter reaction time (99 $\mathrm{min}$ ) at room temperature, compared to the standard solvent-based protocol for amidation (12 h). Apart from an amide as a directing group, several other directing groups (e.g., ketones, ketoximes, 2phenylpyridine, 2-phenylpyrimidine, etc.) were used for the amidation under the optimized reaction conditions. A kinetic isotope study $\left(K_{\mathrm{H}} / K_{\mathrm{D}}=4.4\right)$ indicates that the $\mathrm{C}-\mathrm{H}$ bond cleavage might be the ratedetermining step.
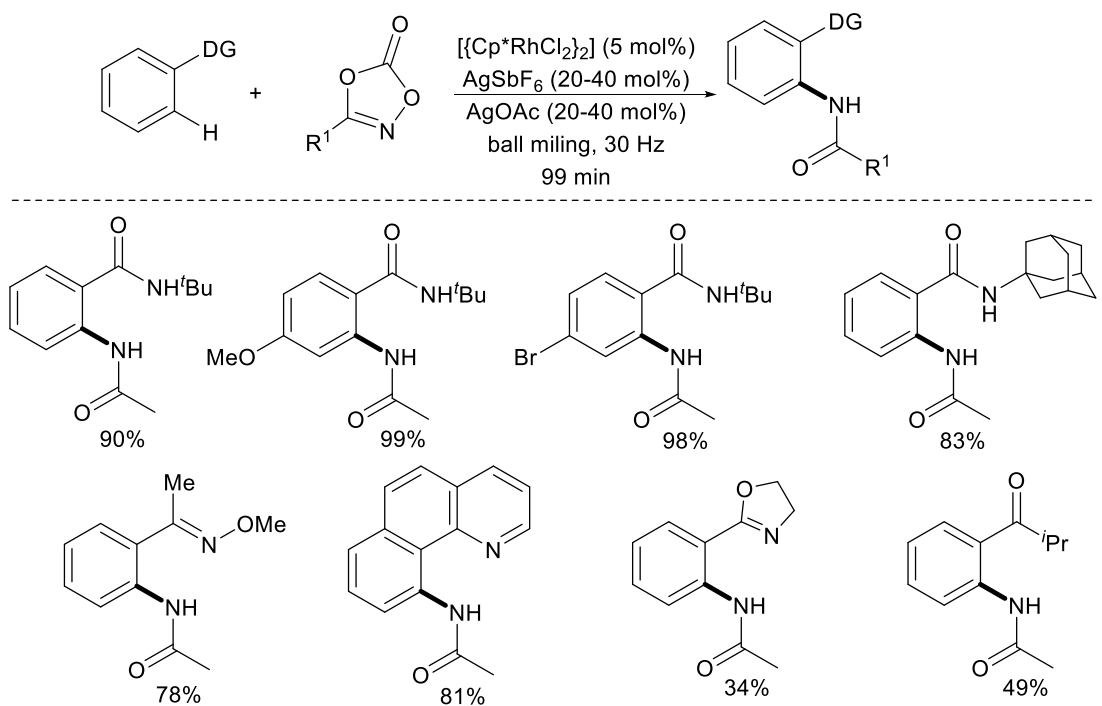

Scheme 5. Rhodium catalyzed mechanochemical C-H bond amidation.

Rhodium(III)-catalyzed C-H bond alkynylation of $\mathrm{N}$-(2-pyrimidyl)indole (13), in which pyrimidine acts as a directing group, was reported by Bolm and co-workers (Scheme 6, Eq 1). ${ }^{29}$ Functionalization of the indole moiety by an alkyne (14) was achieved in the presence of $0.5 \mathrm{~mol} \%$ of $\left[\left\{\mathrm{Cp}^{*} \mathrm{RhCl}_{2}\right\}_{2}\right]$ and $2.0 \mathrm{~mol} \%$ of $\mathrm{AgNTf}_{2}$ under ball milling. The reaction afforded a series of C2-alkynylated indole derivatives (15) in good-to-excellent 
yields within a short time. Both electron-donating and -withdrawing groups such as methyl, methoxy, halogens (fluoro, chloro, bromo and iodo) at the 5-position of the indole, were well tolerated under the mechanochemical reaction conditions. Interestingly, the reaction produces the silyl-protected C2-alkynated indole derivative, which can be applied further for derivatization after deprotection by the silyl group. When a mixture of $\mathrm{N}$-pyrimidylindole (13) and $\left[\left\{\mathrm{Cp}^{*} \mathrm{RhCl}_{2}\right\}_{2}\right]$ along with $\mathrm{NaOAc}$ was milled for $60 \mathrm{~min}$ at $30 \mathrm{~Hz}$ under solvent-free conditions, a rhodacycle intermediate (16) was formed (Scheme 6, Eq 2). Next, the rhodacycle (16) was used as a catalyst in the presence of $\mathrm{AgNTf}_{2}(2.0$ mol\%) for the reaction of 13 and 14 (Scheme 6, Eq. 3). After 60 minutes of milling, indole (15) was obtained in $96 \%$ yield. This result suggests that the reaction proceeds through the formation of 16.

(1)
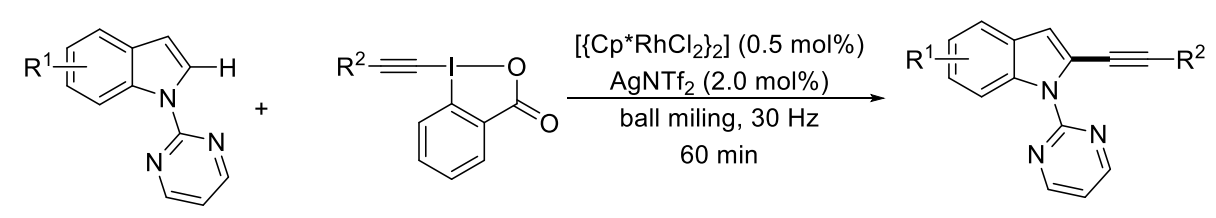

13

14

15
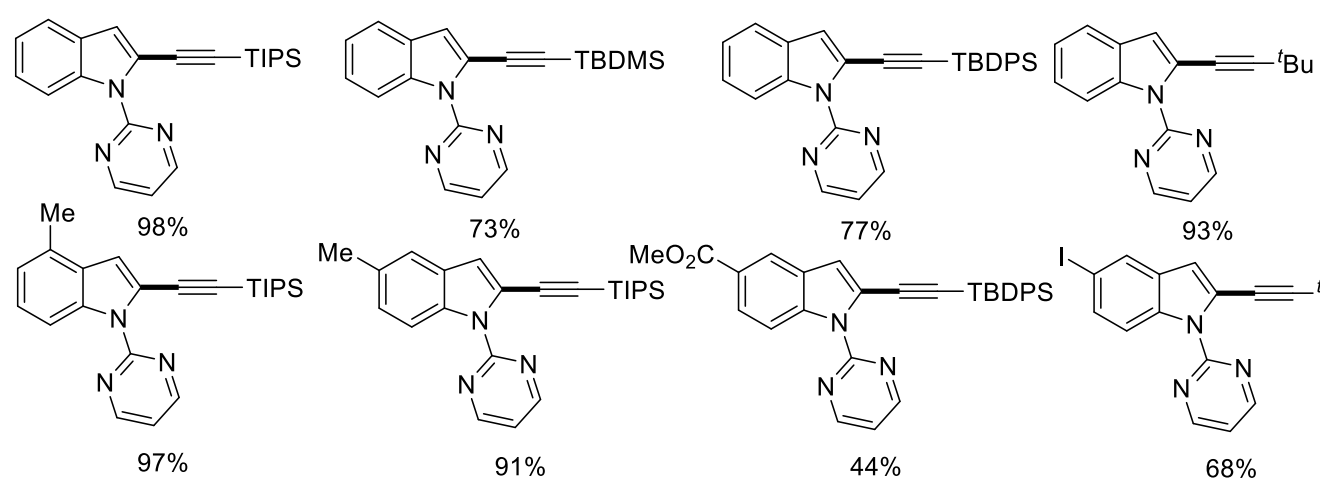

$77 \%$

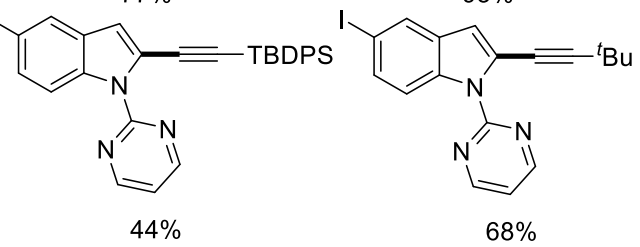

(2)

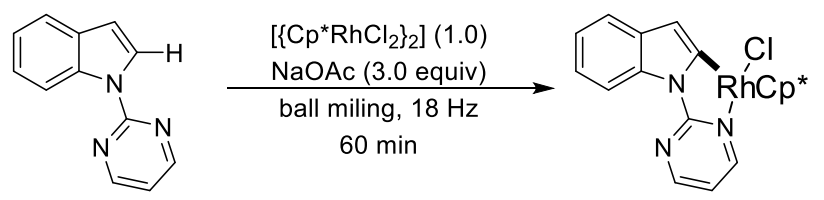

(3)

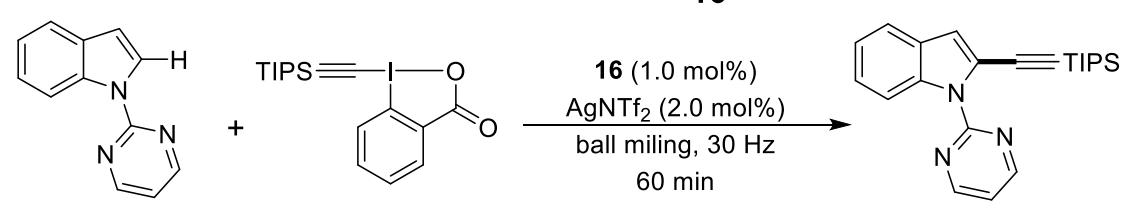

Scheme 6. Rhodium(III)-catalyzed C-H alkynylation of indoles under solvent-free conditions in a mixer mill.

Recently, Li and Wang reported the synthesis of 2-aminoanilides through $\mathrm{C}-\mathrm{H}$ amidation of $\mathrm{N}$ nitrosoanilines (17) under ball milling in the absence of any solvent (Scheme 7). ${ }^{30}$ 1,4,2-Dioxazol-5-ones (18) were used as the amidating agent. 


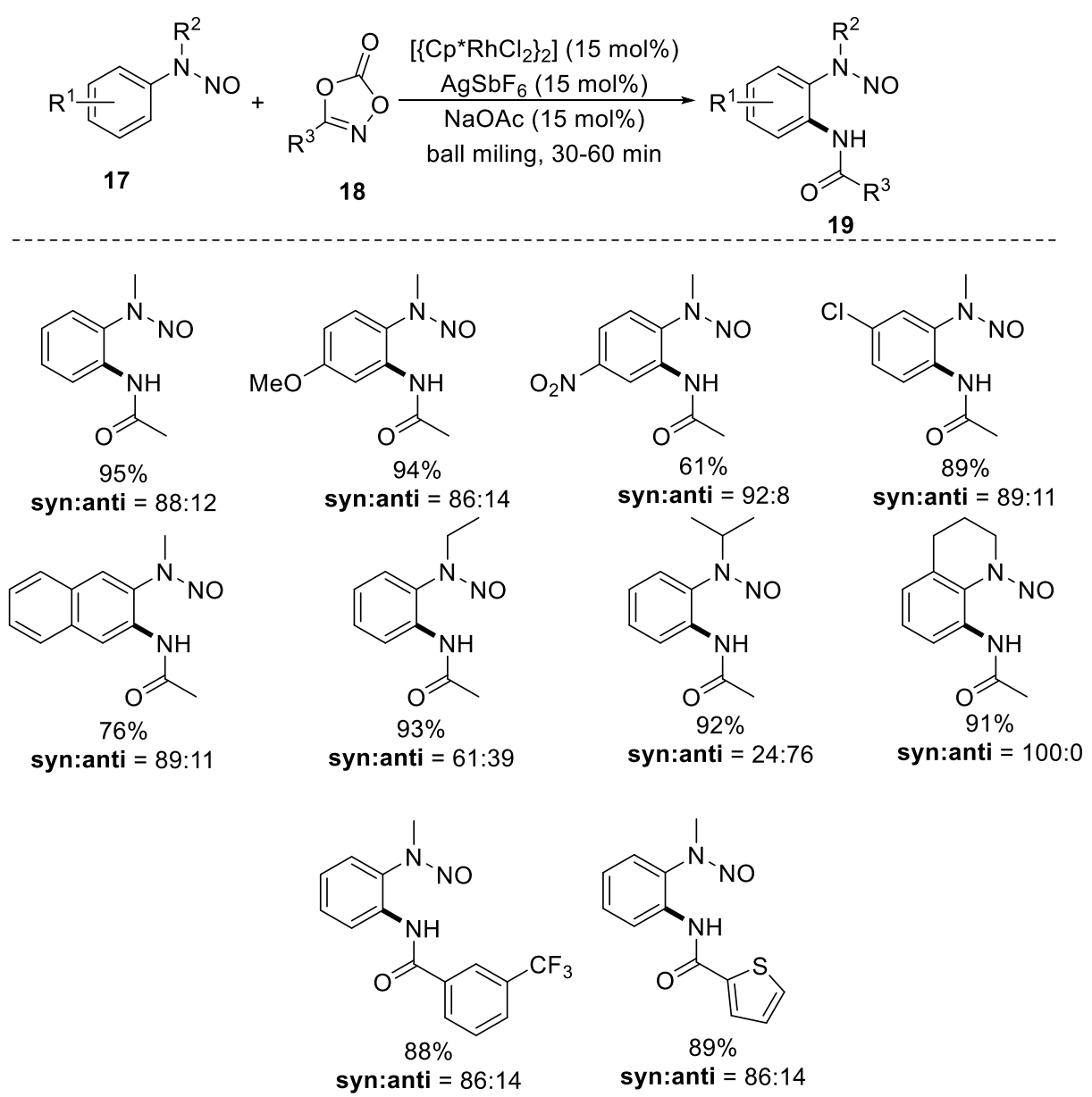

Scheme 7. Solvent-free rhodium(III)-catalyzed synthesis of 2-aminoanilides.

After several optimizations, it was observed that $\left[\left\{\mathrm{Cp}^{*} \mathrm{RhCl}_{2}\right\}_{2}\right]$ is the best catalyst for this transformation compared to other commonly employed catalysts, e.g., Pd, Co and Ir. The reaction requires the use of 1.0 mol\% of $\left[\left\{\mathrm{Cp}^{*} \mathrm{RhCl}_{2}\right\}_{2}\right]$ and $15 \mathrm{~mol} \%$ of $\mathrm{AgSbF}_{6}$, in the presence of $\mathrm{NaOAc}$ (15 mol\%) as an additive, using a stainless-steel ball (10 mm in diameter) in a mixer mill at $30 \mathrm{~Hz}$ for $30-60 \mathrm{~min}$. A range of diversely-substituted $\mathrm{N}$-nitrosoaniline derivatives, bearing both electron-donating and electron-withdrawing groups, underwent successful ortho-C-H amidation with 1,4,2-dioxazol-5-ones bearing an alkyl or aryl moiety. The corresponding amidated derivatives (predominantly syn) (19) were formed in good-to-excellent yields within a short period of time. The gram-scale reactions give as good yields as mmol-scale reactions. A kinetic isotope study, with $K_{\mathrm{H}} / K_{\mathrm{D}}=2.1$, indicates that the ortho- $\mathrm{C}-\mathrm{H}$ bond cleavage might be involved in the rate-determining step. In general, the reaction provides an efficient and environmentally-benign pathway for the synthesis of 2aminoanilide derivatives with low-catalyst loading under rhodium-catalyzed mechanochemical conditions.

\section{Ru-Catalyzed C-H Functionalization}

In 2017, Bolm et al. reported the first mechanochemical $\mathrm{Ru}(\mathrm{III})$-catalyzed $\mathrm{C}-\mathrm{H}$ bond functionalization of acetanilides under ball milling (Scheme 8). ${ }^{31}$ The reaction of an alkyne with acetanilide leads to the formation of tri-substituted $(E)$-alkenes in good yields in the presence of a ruthenium catalyst under solvent-free 
conditions. The reaction requires the use of catalytic amounts of $\mathrm{AgSbF}_{6}$ salt as an oxidant, and pivalic acid or copper acetate as an additive. The corresponding alkene derivatives were formed within a short time. The alkene derivatives were converted into $\mathrm{N}$-acetylindoles by palladium catalyzed $\mathrm{C}\left(s p^{2}\right)-\mathrm{H} / \mathrm{N}-\mathrm{H}$ coupling in the mixer mill.

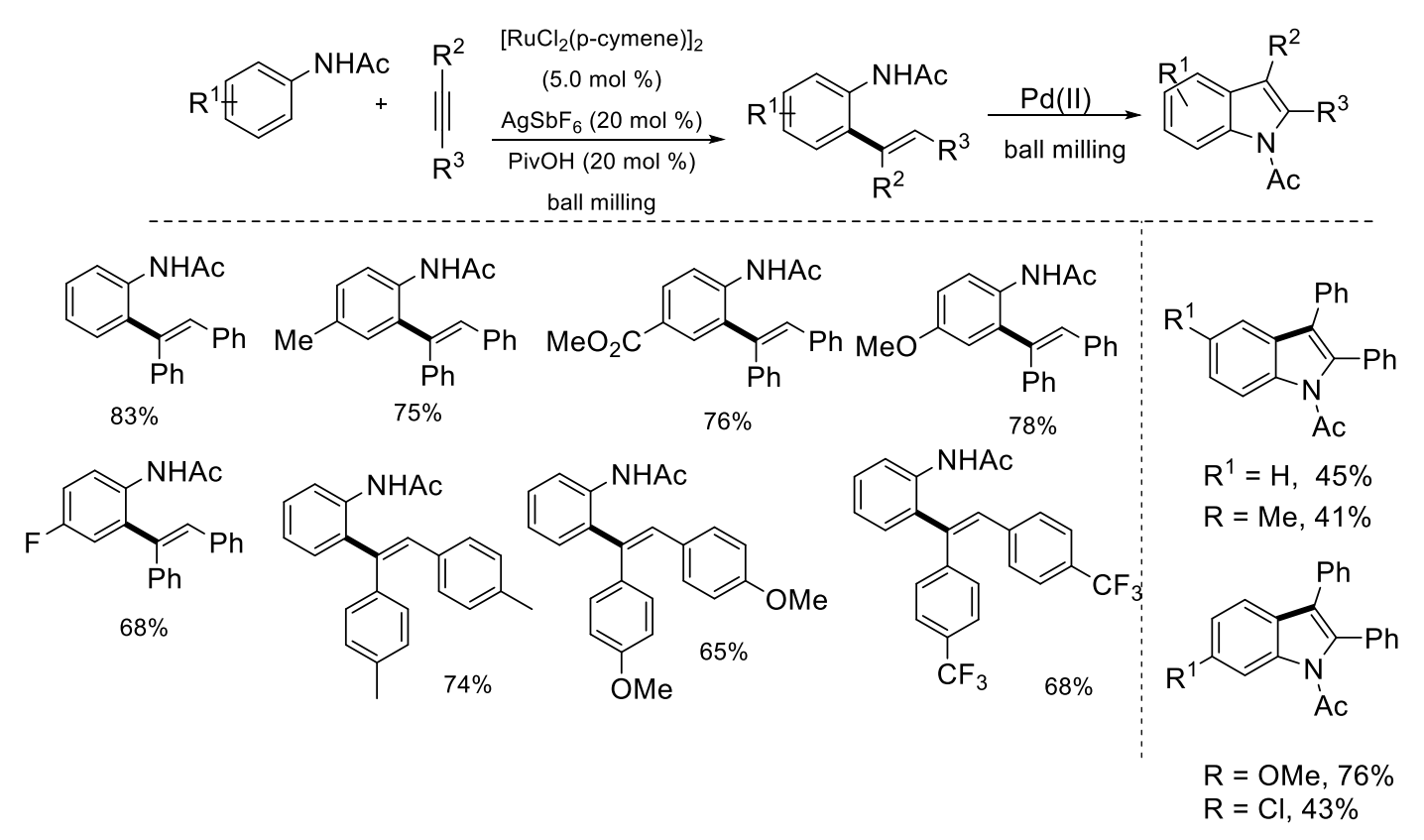

Scheme 8. Mechanochemical ruthenium-catalyzed hydroarylation of alkynes under ball-milling.

\section{Co-Catalyzed C-H Functionalization}

Bolm and his group developed a unique procedure for the synthesis of $\left[\mathrm{Cp} * \mathrm{Co}(\mathrm{CO}) \mathrm{I}_{2}\right]$ under ball milling which was then subsequently used in the amidation of indoles (Scheme 9). ${ }^{32}$ Initially, $\mathrm{Co}_{2}(\mathrm{CO})_{8}$ (20) undergoes reaction with pentamethylcyclopentadiene $(\mathrm{Cp} * \mathrm{H}, \mathbf{2 1})$ in dichloromethane (DCM) to generate the intermediate $\left[\mathrm{Cp}^{*} \mathrm{Co}(\mathrm{CO})_{3}\right](22)$. The $\mathrm{Co}(\mathrm{I})$ intermediate $(\mathbf{2 2})$ then reacts with molecular iodine in diethyl ether to provide the cobalt (III) complex (23). The newly-formed cobalt (III) complex was applied further as a catalyst for the amidation of indoles (24) using 1,4,2-dioxazol-5-one (25) as the amidating agent under solvent-free grinding in a mixer ball mill. The mechanochemical $\mathrm{C}-\mathrm{H}$ bond amidation occurs in the presence of $2.5 \mathrm{~mol} \%$ $\left[\mathrm{Cp}^{*} \mathrm{Co}(\mathrm{CO}) \mathrm{I}_{2}\right.$ ], $5 \mathrm{~mol} \%$ of $\mathrm{AgSbF}_{6}$, and $5 \mathrm{~mol} \%$ of $\mathrm{NaOAc}$ for $99 \mathrm{~min}$ at $30 \mathrm{~Hz}$. A range of amidated indole derivatives (26) was synthesized starting from 1,4,2-dioxazol-5-ones and an indole moiety under the optimized conditions. It was observed that, compared to the previous solution-based protocol, this method offers a more practical and environmentally-benign access to both the cobalt(III) catalyst and 2-amidated indoles. 


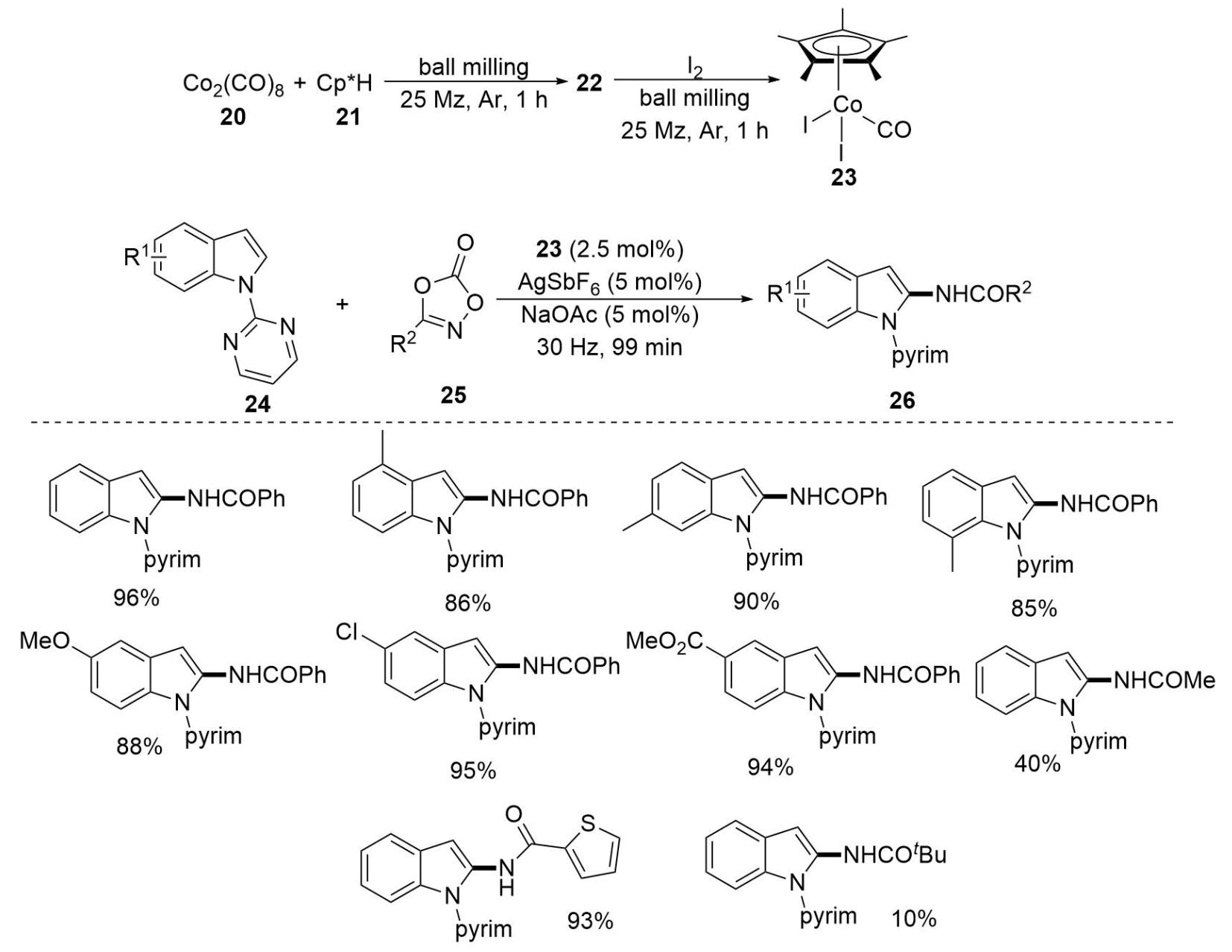

Scheme 9. Cobalt-catalyzed C-H amidation of indoles under ball milling.

\section{Ir-Catalyzed C-H Functionalization}

In addition to $\mathrm{Pd}, \mathrm{Rh}, \mathrm{Ru}$ and Co catalysts, Ir catalysts have also been successfully employed for $\mathrm{C}-\mathrm{H}$ bond functionalization under mechanochemical conditions. In 2016, Bolm and his co-workers developed a mechanochemical C-H amidation of amides with aryl or alkyl sulfonyl azides, using $\left[\mathrm{Cp}^{*} \mid \mathrm{ICl}_{2}\right]_{2}$ as the catalyst in the presence of $\mathrm{Ag}$ salt as an oxidant, under ball milling for the first time (Scheme 10). ${ }^{33}$ The reactions involve the interaction of an amide derivative and sulfonyl azides in the presence of $\left[\mathrm{Cp}^{*} \mid \mathrm{ICl}_{2}\right]_{2}(2.5 \mathrm{~mol} \%), \mathrm{AgBF}_{4}(10$ mol\%) and AgOAc (10 mol\%) under ball milling. A range of diversely-substituted aromatic amides reacted with both aryl and alkyl sulfonyl azides under the optimized reaction conditions, and the corresponding ortho- $\mathrm{C}-\mathrm{H}$ amidated derivatives were formed in good-to-excellent yields. Intermolecular-competition experiments revealed the slightly lower reactivity of electron-rich azides compared with electron-deficient ones. 


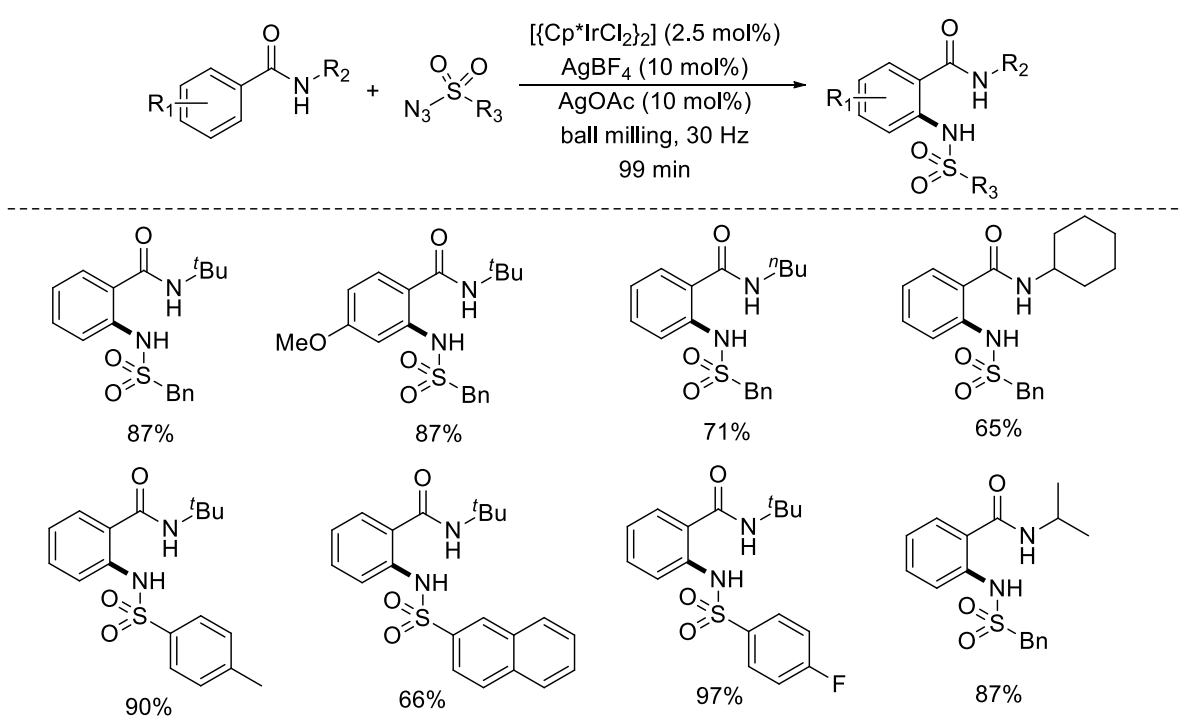

Scheme 10. Mechanochemical Ir-catalyzed C-H bond amidation of amides.

\section{Conclusions}

Functionalization via C-H activation is, in itself, a green concept since it eliminates molecule prefunctionalization steps, thereby, helping to reduce the numbers and amounts of reagents and solvents used. When this is coupled with an energy- and cost-saving tool such as ball milling, its importance and value are definitely enhanced. This brief account demonstrates various types of functionalization via $\mathrm{C}-\mathrm{H}$ activation using a variety of transition-metal catalysts under ball milling. We believe it will attract the attention of synthetic chemists and will find further applications in organic synthesis.

\section{Acknowledgements}

Financial support from Indian National Science Academy, New Delhi, under the offer of an INSA Senior Scientist position to B.C.R., is gratefully acknowledged. S.J. sincerely thanks the Science Engineering Research Board (SERB), Department of Science and Technology for his National Post Doctoral Fellowship.

\section{References}

1. Gupta, P.; Mahajan, A.; RSC Adv. 2015, 5, 26686.

2. Varma, PS. Green Chem. 2014, 16, 2027. https://doi.org/10.1039/c3gc42640h

3. Leisch, H.; Morley, K.; Lau, PC.; Chem. Rev. 2011, 111, 4165. https://doi.org/10.1021/cr1003437 
4. James, S. L.; Adams, C. J.; Bolm, C.; Braga, D.; Collier, T.; Frišč̌ic', F.; Grepioni, K. D. Harris, M.; Hyett, G.; Jones, W.; Krebs, A.; Mack, J.; Maini, L.; Orpen, A. G.; Parkin, I. P.; Shearouse, W. C.; Steed, J. W.; Waddell, D. C. Chem. Soc. Rev. 2012, 41, 413. https://doi.org/10.1039/C1CS15171A

5. Beyer, M. K.; Clausen-Schaumann, H. Chem. Rev. 2005, 105, 2921. https://doi.org/10.1021/cr030697h

6. Ribas-Arino, J.; Marx, D. Chem. Rev. 2012, 112, 5412. https://doi.org/10.1021/cr200399q

7. Howard, J. L.; Cao, Q.; Browne, D. L. Chem. Sci. 2018, 9, 3080. https://doi.org/10.1039/C7SC05371A

8. Stolle, A. Technical Implications of Organic Synthesis in Ball Mills, in Ball Milling Towards Green Synthesis, ed. B. Ranu, A. Stolle, The Royal Society of Chemistry, Cambridge, 2015, P001-P006 ISBN: 978-1-84973945-0 and references cited therein.

9. Hernandez, J. G.; Friščić, T. Tetrahedron Lett. 2015, 56, 4253. https://doi.org/10.1016/i.tetlet.2015.03.135

10. Engle, K. M.; Mei, T.-S.; Wang, X.; Yu, J.-Q. Angew. Chem., Int. Ed. 2011, 50, 1478. https://doi.org/10.1002/anie.201005142

11. Lyons, T. W.; Sanford, M. S. Chem. Rev. 2010, 110, 1147. https://doi.org/10.1021/cr900184e

12. Gutekunst, W. R.; Baran, P. S. Chem. Soc. Rev. 2011, 40, 1976. https://doi.org/10.1039/c0cs00182a

13. Ackermann, L. Chem. Rev. 2011, 111, 1315. https://doi.org/10.1021/cr100412j

14. Baudoin, O. Chem. Soc. Rev. 2011, 40, 4902. https://doi.org/10.1039/c1cs15058h

15. Labinger, J. A.; Bercaw, J. E. Nature 2002, 417, 507. https://doi.org/10.1038/417507a

16. Godula, K.; Sames, D. Science 2006, 312, 67. https://doi.org/10.1126/science.1114731

17. McDonald, R. I.; Liu, G. S.; Stahl, S. S. Chem. Rev. 2011, 111, 2981. https://doi.org/10.1021/cr100371y

18. Arndtsen, B. A.; Bergman, R. G.; Mobley, T. A.; Peterson, T. H. Acc. Chem. Res. 1995, 28, 154. https://doi.org/10.1021/ar00051a009

19. Pototschnig, G.; Maulide, N.; Schnerch, M. Chem. Eur. J. 2017, 23, 9206. https://doi.org/10.1002/chem.201605657

20. Shang, R.; Ilies, L.; Nakamura, E. Chem. Rev. 2017, 117, 9086. https://doi.org/10.1021/acs.chemrev.6b00772

21. Wang, S.; Chen, S.-Y.; Yu, X.-Q. Chem. Commun. 2017, 53, 3165. https://doi.org/10.1039/C6CC09651D

22. Friščić, T.; Childs, S. L.; Rizvi, S. A. A.; Jones, W. CrystEngComm 2009, 11, 418. https://doi.org/10.1039/B815174A

23. Hernandez, J. G. Chem. Eur. J. 2017, 23, 17157 and references cited therein. https://doi.org/10.1002/chem.201703605

24. Juribašić, M.; Užarević, K.; Gracin, D.; Ćurić, M.; Chem. Commun. 2014, 50, 10287. 
https://doi.org/10.1039/C4CC04423A

25. Liu, Z.; Xu, H.; Wang, G.-W. Beilstein J. Org. Chem. 2018, 14, 430.

https://doi.org/10.3762/bjoc.14.31

26. Weng, Y.; Lan, T.; Sun, C.; Yang, T.; Sua, W.; Xie, Y. Org. Chem. Front. 2018, 5, 2103.

https://doi.org/10.1039/C8Q000420J

27. Hernández, J. G.; Bolm, C. Chem. Commun. 2015, 51, 12582.

https://doi.org/10.1039/C5CC04423E

28. Hermann, G. N.; Bolm, C. ACS Catal. 2017, 7, 4592.

https://doi.org/10.1021/acscatal.7b00582

29. Hermann, G. N.; Unruh, M. T.; Jung, S.-H.; Krings, M.; Bolm, C. Angew.Chem. Int. Ed. 2018, 57, 10723. https://doi.org/10.1002/anie.201805778

30. Li, L.; Wang, G.-U. Tetrahedron 2018, 74, 4188.

https://doi.org/10.1016/j.tet.2018.06.003

31. Cheng, H.; Hernández, J.-G.; Bolm, C. Org. Lett. 2017, 19, 6284.

32. Cheng, H.; Hernández, J.-G.; Bolm, C. Adv. Synth. Catal. 2018, 360, 1800.

33. Hermann, G. N.; Becker, P.; Bolm, C. Angew. Chem. Int. Ed. 2016, 55, 3781

https://doi.org/10.1002/anie.201511689.

\section{Authors' Biographies}

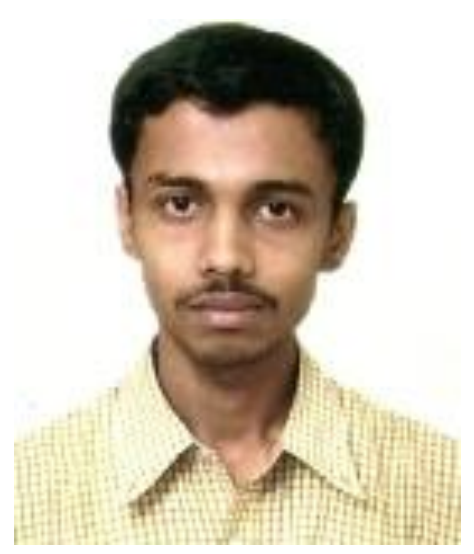

Tubai Ghosh completed his B.Sc (Chemistry Hons.) from Hooghly Mohsin College, The University of Burdwan in 2010. He obtained M.Sc (2 yr) in Chemistry degree from IIT Kanpur in 2012. Currently he is working as a senior research fellow in the group of Professor B. C. Ranu at the School of Chemical Sciences, Indian Association for the Cultivation of Science, Jadavpur, Kolkata, India. His current research focuses on the transition-metal-catalyzed $\mathrm{C}-\mathrm{H}$ bond functionalization. 


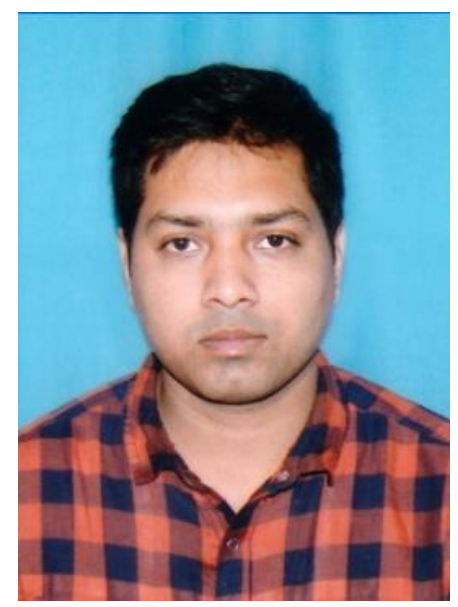

Swapnadeep Jalal was born in Burdwan (West Bengal), India. He obtained his B. Sc. and M. Sc. degrees from The University of Burdwan, India, in 2008 and 2010, respectively. He received his Ph. D. degree from Jadavpur University (Kolkata), India in 2017. His research focuses on the synthesis of bioactive heterocyclic and polycyclic ring compounds by cross coupling reactions and alkyne/alkene carbonyl metathesis reaction using transition-metal catalyst. He is currently working under Professor B. C. Ranu, School of Chemical Sciences, IACS, Kolkata, India, as a DST-NPDF Fellow. He is also continuing as guest lecturer at P.G Department of Chemistry, Vivekananda Mahavidyalaya under The University of Burdwan, West Bengal, India since 2014.

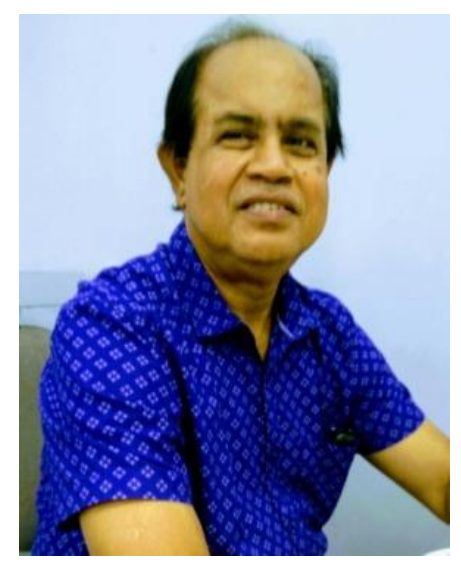

Brindaban C. Ranu started his independent research career in 1985 at the Department of Organic Chemistry, Indian Association for the Cultivation of Science, Jadavpur, Kolkata, India after completion of his graduate studies at Rice University (mentor - Professor E. Wenkert), Houston, Texas, USA and IACS, Kolkata (mentor Professor U. R. Ghatak) and postdoctoral work at Virginia Tech, USA (mentor - Professor T. Hudlicky). His research interests include Green Synthesis and Green Catalysis. He became professor in 1996 and Senior Professor in 2006. Currently he is INSA Senior scientist. He received the Chemical Research Society of India silver medal in 2010. He was elected fellow of the Indian Academy of Sciences in 1995 and fellow of the Indian National Science Academy in 2008. He is also a recipient of J C Bose National Fellowship, DST, Govt. of India. He has published more than 275 papers. 